\title{
Geotechnical engineering characteristics of 'Polishing Sand' in Handa area, Japan
}

\author{
Takahisa Nishioka $^{\text {i), Satoru Shibuya }}{ }^{\text {ii)}}$, Satuski Kataoka ${ }^{\text {iii)}}$, Tomoya Kitano ${ }^{\text {iv) }}$, and Nidhi Lohani ${ }^{\text {v) }}$ \\ i) General Manager, KYOWA SEKKEI Co. Ltd, 2-1-34, Ushitora, Ibaraki-shi, Osaka, Japan. \\ ii) Professor, Department of Civil Engineering, Graduate School of Engineering, Kobe University, 1-1, Rokkodaicho, Nada-ku, Kobe- \\ shi, Hyogo, Japan. \\ iii) Assistant Professor, Kobe University, 1-1, Rokkodaicho, Nada-ku, Kobe-shi, Hyogo, Japan. \\ iv) Student, Kobe University, 1-1, Rokkodaicho, Nada-ku, Kobe-shi, Hyogo, Japan. \\ v) Technical Staff, Kobe University, 1-1, Rokkodaicho, Nada-ku, Kobe-shi, Hyogo, Japan.
}

\begin{abstract}
Engineering properties of local soil called 'Polishing sand' distributed over the southern district of Tsu-shi in Mie Prefecture was examined by performing laboratory tests. Polishing sand at natural state is found as a sedimentary soft rock with average strength parameters, $\mathrm{q}_{\mathrm{u}}=0.2$ to $3.4 \mathrm{MPa}, \mathrm{c}_{\mathrm{cu}}=100$ to $200 \mathrm{kPa}, \phi_{\mathrm{cu}} \geq 40 \sim 50$ degrees and it transforms into a homogeneous grayish-white sand when exposed to the surface by excavation. Looking on the average strength parameters of the disintegrated sand, $\mathrm{c}_{\mathrm{cu}}=10 \mathrm{kPa}, \varphi_{\mathrm{cu}}=36^{\circ}$, a drop in $\mathrm{q}_{\mathrm{u}}$ to almost $1 / 10$ or smaller level than that at natural state is observed. The difference in properties of these two states of the same material are considered to be due to cementation and crystallization effects between soil particles. When in a natural state, the anisotropy evaluated by triaxial tests with bender elements shows $\mathrm{G}_{\mathrm{hh}} / \mathrm{G}_{\mathrm{vh}}=1.4 \sim 1.5$ at mean effective confining pressure, $\mathrm{p}^{\prime}=0 \sim 100 \mathrm{kPa}$ and $\mathrm{G}_{\mathrm{hh}} / \mathrm{G}_{\mathrm{vh}} \approx 1.0$ at $100<\mathrm{p}^{\prime} \leq 400 \mathrm{kPa}$. This shows an anisotropic behavior at deposition because of cementation and its destructuration afterwards at higher confining pressure. Additionally, the relation between $\mathrm{q}_{\mathrm{u}}$ and $\mathrm{G}$ has been elaborated by comparing it with cement-treated soil and by discussing physical and chemical aspects of cementation.
\end{abstract}

Keywords: Polishing sand, reconstituted soil, volcanic cohesive soil, shear modulus, cementation

\section{INTRODUCTION}

Local soil called as polishing sand (hereafter called as Polishing sand) is widely distributed in Handa area of Tsu city, Mie Prefecture (Fig.1). It is said that the sand was quite familiar in the surrounding area because of its use as a toothpaste and also as a detergent before the synthetic products appeared in the market. Nowadays, this sand is produced only in a very small quantity in order to use as an abrasive material in metal industries.

Mining of Polishing sand is found to have begun in the Edo period and continued through the Meiji period until the early Showa period. In the earlier period, the mines were relatively narrow having 2 to $3 \mathrm{~m}$ in both width and height. However, from the year 1965 and onwards, open pit by using heavy equipment had become common (Isobe, 1993). As those tunnels and outcrops were freely standing without any treatment and support, it can be inferred that the original bedrock was quite stiff and of high strength. Quantitative strength data were however not investigated and therefore, remain unknown. On the other hand, the problem of sudden collapse of the ground developed for residential purpose and roads over those abandoned mining cavities are on the rise suggesting the deterioration of original bedrock.
Until now, there are not much studies on geotechnical aspects of this sand and its use for engineering purpose. It was therefore considered very important to understand the behavior of Polishing sand and the authors are investigating the characteristics of this unique sand by means of laboratory tests (Nishioka et al., 2015). In this paper, we have also introduced a new finding about the difference between the in-situ and reconstituted samples by performing a bender element test.

\section{POLISHING SAND GEOLOGIC FORMATION}

Polishing sand is the most recent deposit of Akogi volcanic ash layer corresponding to the bottom of the Kameyama formation of Tokai Group, deposited in the Pliocene to early Pleistocene period at and around Ise Bay. Yoshida (1987) suggests Akogi volcanic ash layer thickness as 5 to $18 \mathrm{~m}$ and its inclination as 2 to $5^{\circ}$ northward. Almost horizontal stratification is quite apparent in the outcrops on the surface (Fig.2).

The fission-track dating (FT) of Polishing sand is considered as 4.6 $\pm 2 \mathrm{Ma}$ (Mega-annum) (Yoshida, 1987). Although the aspect of its origin is not clear, Isobe (1993) speculates the original source as Nijo volcano, and subsequent deposition of sedimentary soil layers on 
its top because of the geological surface depression, such as lake. Exhibiting grayish-white color and also known as Akogi volcanic ash layer, it is composed of 97 to $99 \%$ glass, $1-2 \%$ of feldspar and $0-1 \%$ quartz (Yoshikawa, 2001).

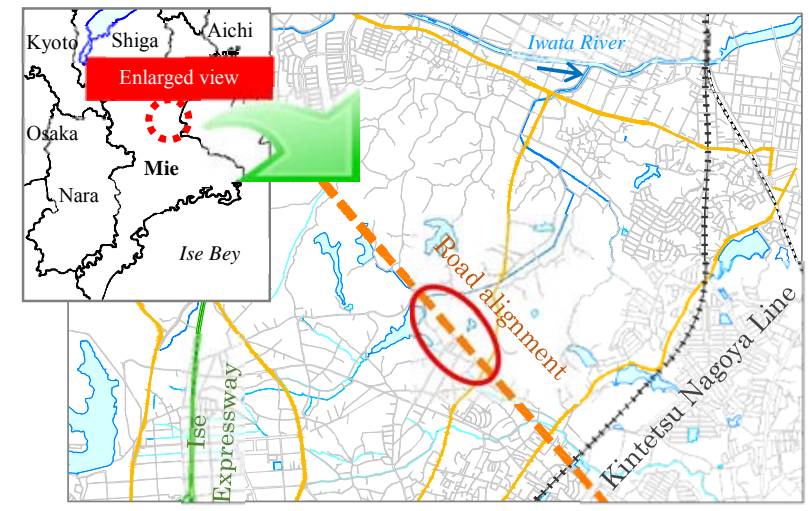

Fig. 1. Location of Handa area of Tsu City.

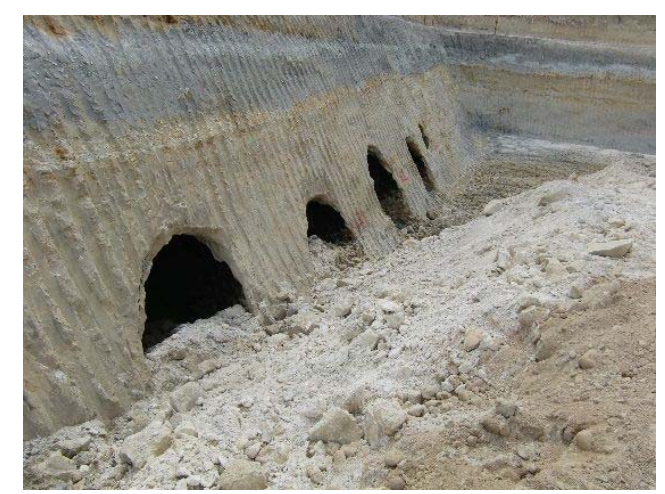

Fig. 2. Traces of abandoned Polishing sand mines

\section{PHYSICAL PROPERTIES}

Table 1 shows the physical properties of Polishing sand at loosened state and Fig. 3 shows its grain-size distribution curve.

Table 1. Physical property of the Polishing sand.

\begin{tabular}{ll}
\hline Item & Value from the test \\
\hline Specific Gravity (Gs) & $2.407 \sim 2.487 \quad(2.440)$ \\
\hline \multirow{2}{*}{ Particle size distribution (\%) } & Gravel : $0 \sim 0.3(0.0)$ \\
& Sand : 2.4 27.4 (11.4) \\
& Silt : 65.5 84.5 (77.0) \\
& Clay : 7.1 17.3 (11.5) \\
& Fines : 72.6 97.3 (88.6) \\
\hline Natural water content (\%) & $34.3 \sim 48.7 \quad(41.0)$ \\
\hline Liquid limit/Plastic limit & NP \\
\hline & \multicolumn{1}{c}{ Inside ( ) is average value }
\end{tabular}

Polishing sand is a relatively uniform soil having uniformity coefficient, Uc in the range of 5.0 to 13.0 (average 6.9) and average fine fraction, $\mathrm{Fc}=89 \%$ that is mostly composed of silt fraction. With the gravel proportion just within $10 \%$ and devoid of clay minerals, it is classified as volcanic ash fine-grained soil(reference J.S.E.L.). Specific gravity of soil particles, $\mathrm{G}_{\mathrm{s}}=2.44$ is quite small. The natural moisture content lies in the range of $34-49 \%$ and is a non-plastic (NP) soil.

The void ratio of Polishing sand ranges from 1.03 to 1.21 (average 1.12) in its natural state, which is quite large as compared to ordinary soils. On the other hands, its wet density value in the range of $1.59 \sim 1.71 \mathrm{~g} / \mathrm{cm}^{3}$ (average $1.65 \mathrm{~g} / \mathrm{cm}^{3}$ ) is rather small.

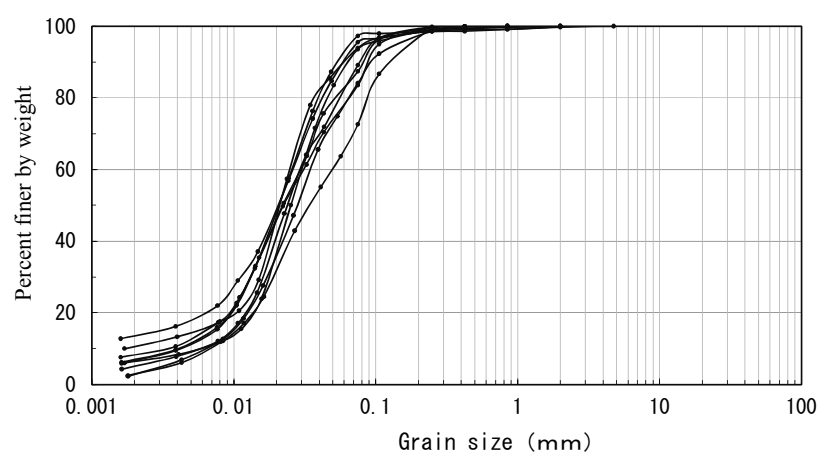

Fig. 3. Grain size distribution curve of Polishing sand

\section{STRENGTH PROPERTIES}

\subsection{Unconfined compression strength}

Table 2 shows a uniaxial compression test result on undisturbed and reconstituted Polishing sand samples, $10 \mathrm{~cm}$ in height and $5 \mathrm{~cm}$ in diameter. Undisturbed samples were prepared by trimming the soil blocks collected from the site by using block sampling method. In order to prepare the disturbed samples, sampled blocks were first pulverized by mallet and then passed through $2 \mathrm{~mm}$ sieve. Static compaction was done in three layers by using a hydraulic jack with the target density of $1.013 \mathrm{~g} / \mathrm{cm}^{3}\left(0.9 * \rho_{\mathrm{dmax}}\right)$.

Table 2. Unconfined compression strength of the Polishing sand. State of the sample Unconfined compression strength $\mathrm{q}_{\mathrm{u}}(\mathrm{kPa})$ Undisturbed sample 228 3,409

\begin{tabular}{ll}
\hline $\mathrm{Dc}=85 \%$ & 18.2 \\
\hline $\mathrm{Dc}=90 \%$ & 25.3 \\
\hline $\mathrm{Dc}=95 \%$ & 44.4 \\
\hline
\end{tabular}

Polishing sand in the natural state is a stiff soil and shows the uniaxial compressive strength about 0.2 3.4MPa. Large variations in strength were observed that suggests the effect of sample disturbance and stress release at the time of sampling. On the contrary, reconstituted samples show $\mathrm{q}_{\mathrm{u}}=25 \mathrm{kPa}$ at degree of compaction, $\mathrm{Dc}=90 \%$ that is considerably smaller than that at the natural state. Here, Dc is calculated by comparing the dry density of samples against the standard compaction test result (optimum water content, $\mathrm{w}_{\mathrm{opt}}=37.8 \%$, the maximum dry density, $\rho_{\mathrm{dmax}}=1.126 \mathrm{~g} / \mathrm{cm}^{3}$ ) performed according to Japanese standard, JISA1210 (A-c).

Fig. 4 is a graph showing the relationship between 
axial strain, $\varepsilon a$ and compressive strength, q. Although dry density $\rho_{d}$ and void ratio e is almost the same for both disturbed and undisturbed samples, the undisturbed samples showed relatively brittle type of failure at smaller axial strain. The higher strength associated with the undisturbed samples are considered to be due the cementation.

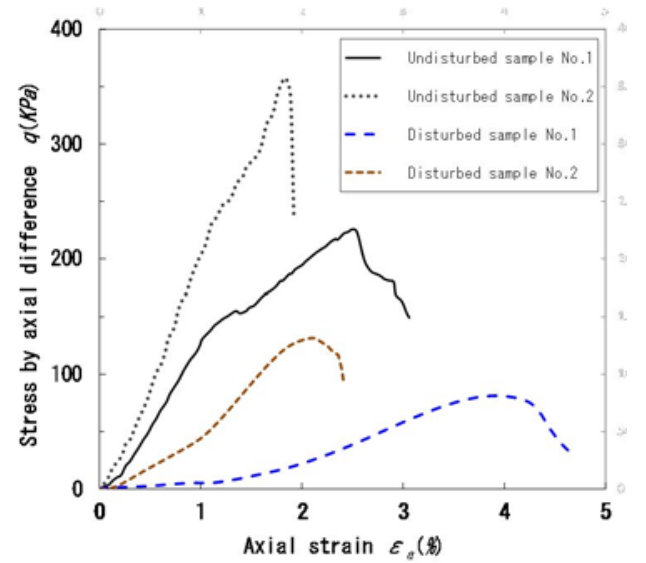

Fig. 4. Relation between unconfined compression strength (q) and axial strain.

\subsection{Triaxial compressive strength}

Table 3 shows the triaxial compressive strength of undisturbed and reconstituted samples. In the natural state, the shear strength, $c_{\mathrm{cu}}, \mathrm{c} \approx 100 \sim 200 \mathrm{kPa}, \varphi_{\mathrm{cu}}$, $\varphi^{\prime} \geq 40 \sim 50^{\circ}$, which is almost equivalent to the strength of rock. On the other hand, when reconstituted at natural water content and degree of compaction, $\mathrm{Dc}=90 \%$, the shear strength parameters fall sharply to $\mathrm{c}_{\mathrm{cu}}=10 \mathrm{kPa}$, $\varphi_{\mathrm{cu}}=36^{\circ}, \quad c^{\prime}=12 \mathrm{kPa}, \varphi^{\prime}=38^{\circ}$. Thus the shear strength values (both $\mathrm{c}_{\mathrm{cu}}$ and $\mathrm{c}^{\prime}$ ) reduced by $1 / 10^{\text {th }}$ of that of the undisturbed sample and angle of friction fell in the range of granular materials.

Table 3. Triaxial compressive strength of the Polishing sand.

\begin{tabular}{ll|l|l|l}
\hline State of the sample & $\mathrm{c}_{\mathrm{cu}}(\mathrm{kPa})$ & $\phi \mathrm{cu}\left({ }^{\circ}\right)$ & $\mathrm{c}^{\prime}(\mathrm{kPa})$ & $\left.\phi{ }^{\prime}{ }^{\circ}\right)$ \\
\hline
\end{tabular}
\begin{tabular}{lll|l|l|l|}
\hline Undisturbed sample & $99 \sim 221$ & $43.2 \sim 57.2$ & $103 \sim 233$ & $44.1 \sim 54.9$ \\
\hline
\end{tabular} \begin{tabular}{l|l|l|l|l|}
\hline Disturbed sample(wn) & $2.5 \sim 16.8$ & $35.0 \sim 37.8$ & $8.7 \sim 16.3$ & $37.6 \sim 39.0$ \\
\hline
\end{tabular}

\subsection{Shear modulus}

Shear modulus $(\mathrm{G})$ is calculated by using the shear wave velocity measured in the bender element test $(\mathrm{V})$ Equation (1).

$$
\mathrm{G}=\rho_{\mathrm{t}} . \mathrm{V}^{2} \quad\left(\rho_{\mathrm{t}}\right. \text { :wet density) }
$$

Fig. 5 is the relationship of the shear modulus $\mathrm{G}$ and uniaxial compressive strength, $\mathrm{q}_{\mathrm{u}}$ of undisturbed samples and disturbed samples of varying degree of compaction. Although having large difference in strength properties as described above, a tendency is clear for the relationship between $\mathrm{G}$ and $\mathrm{q}_{\mathrm{u}}$ and may be expressed using an exponential function (see Fig.5).

Fig. 6 is a relationship between the ratio of shear moduli in horizontal and vertical direction, $\mathrm{G}_{\mathrm{hh}} / \mathrm{G}_{\mathrm{vh}}$, and the average effective confining pressure, $\mathrm{p}^{\prime}$ of undisturbed sample. Although no large change in the void ratio, e is noticed in Polishing sand while loading, in order to remove the effect of void ratio, e on shear modulus, normalization of was done by using a void ratio function proposed by Shibuya and Tanaka (1996), $\mathrm{f}(\mathrm{e})=\mathrm{e}^{-1.5}$. Fig. 7 shows the relationship of $\mathrm{G}_{\mathrm{hh}} / \mathrm{e}^{-1.5}$ and $\mathrm{G}_{\mathrm{vh}} / \mathrm{e}^{-1.5}$. In addition, the relationship of these $\mathrm{G}$ values against $\mathrm{p}^{\prime}$ is shown in Fig. 8.

Fig. 6 shows triaxial compression test with bender elements on undisturbed samples. The ratio of shear moduli representing the stiffness in horizontal and vertical direction, $\mathrm{G}_{\mathrm{hh}} / \mathrm{G}_{\mathrm{vh}}=1.4 \sim 1.5$ under an average effective confining pressure, $\mathrm{p}^{\prime}=0 \sim 100 \mathrm{kPa}$ and $\mathrm{G}_{\mathrm{hh}} / \mathrm{G}_{\mathrm{vh}} \approx 1.0$ at $100<\mathrm{p}^{\prime} \leq 400 \mathrm{kPa}$ range shows the structural changes and disappearance of the anisotropy because of the exceedance of applied confining pressure level. This tendency is similar in Fig. 7 as well. In Fig. 8, the $\mathrm{G} / \mathrm{e}^{-1.5}$ variation is substantially horizontal and hardly associated with increased confining pressure until $\mathrm{p}^{\prime}<=$ $100 \mathrm{kPa}$. The change in $\mathrm{G} / \mathrm{e}^{-1.5}$ value appears in between 100 to $400 \mathrm{kPa}$ range thus following somewhat bilinear model. Kawajiri et al. (2013) has approximated the relationship with a straight line (gradient $\mathrm{n}=0.4 \sim 0.5$ ) regardless of the stress path and geomaterial type itself showing the difference from the general trend.

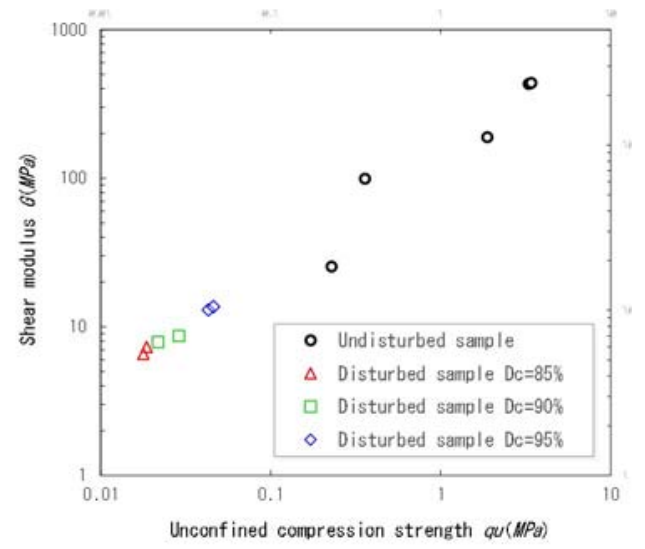

Fig. 5. Relation between $\mathrm{q}_{\mathrm{u}}$ and $\mathrm{G}$

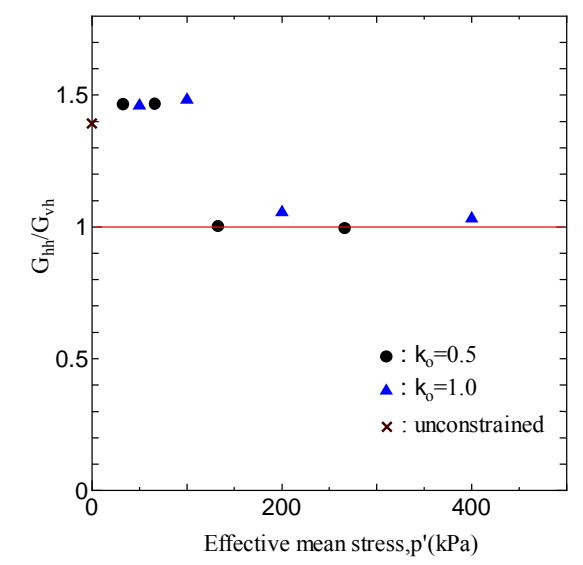

Fig. 6. Relation between $\mathrm{G}_{\mathrm{hh}} / \mathrm{G}_{\mathrm{vh}}$ and $\mathrm{p}$ ' 


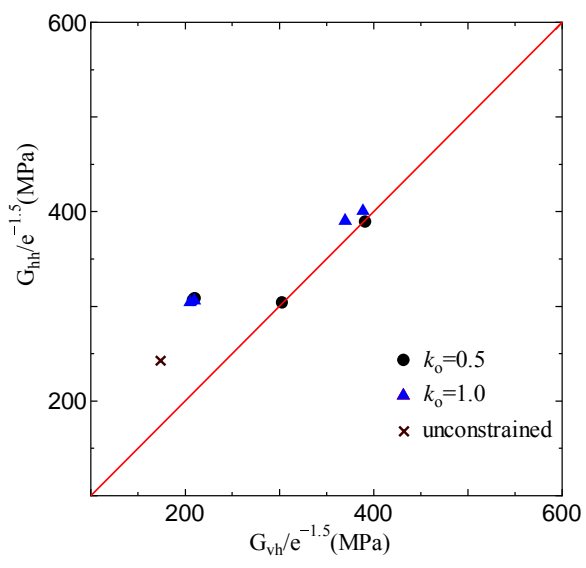

Fig. 7. Relation between $\mathrm{G}_{\mathrm{hh}} / \mathrm{e}^{-1.5}$ and $\mathrm{G}_{\mathrm{vh}} / \mathrm{e}^{-1.5}$

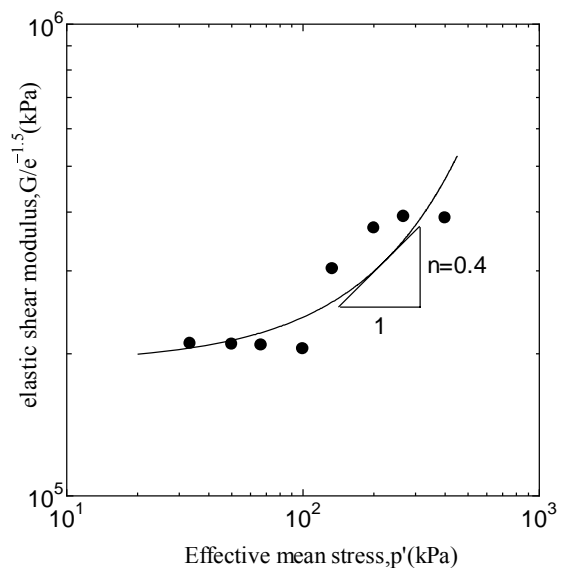

Fig. 8. Relation between $\mathrm{G} / \mathrm{e}^{-1.5}$ and $\mathrm{p}$ '

Such a strong anisotropy (high $\mathrm{G}_{\mathrm{hh}} / \mathrm{G}_{\mathrm{vh}}$ value) shown by Polishing sand at its natural state explains the formation process of Polishing sand. Regarding the hypothesis for supporting anisotropic deposition structure, it is said that the volcanic ash from the surrounding area had flown down along two water streams and deposited into the low-lying depression (Isobe, 1993). The crystallization and cementation between soil particles with the age might have then developed in the horizontal direction along the deposition surface. On the other hand, these ageing effects are damaged when exposed to an increased confining pressure and the disappearance of anisotropy is noted.

Somewhat complex behavior seen in Fig. $7 \mathrm{G} / \mathrm{e}^{-1.5} \sim \mathrm{p}^{\prime}$ relationship could imply that although progress of damage or destruction of cementation continues along with the stress increase, these will not occur evenly. Besides, higher value of shear wave velocity might be measured during the test showing a stronger sample if the wave passes through the stronger portion of soil skeleton that is yet to be broken.

\section{STRENGTH INCREASE BY CEMENT ADDITION}

\subsection{Artificial strength increase with cement}

As given in preceding paragraphs, there is a large difference in mechanical properties between the Polishing sand samples at natural state and those reconstituted afterwards. It is accepted that the sand in its natural state includes the following ageing effects developed with the geological age; i) cementation between soil particles, and ii) crystallization at molecular level. In other words, it is a cementation effect between soil particles driven by physical actions along the long geological era.

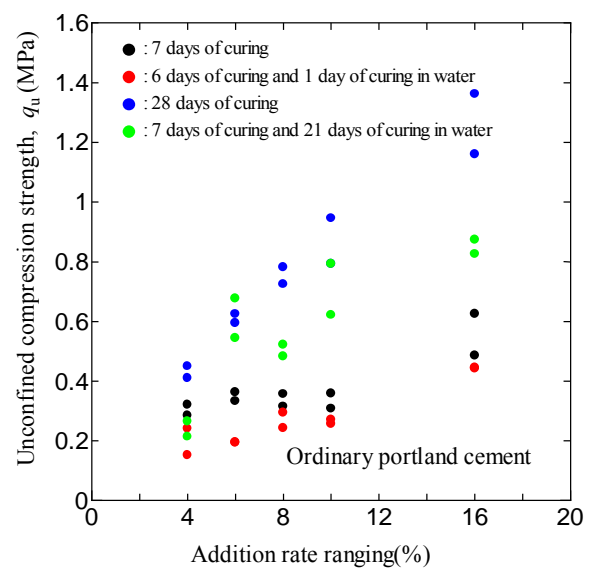

(a) Ordinary Portland cement

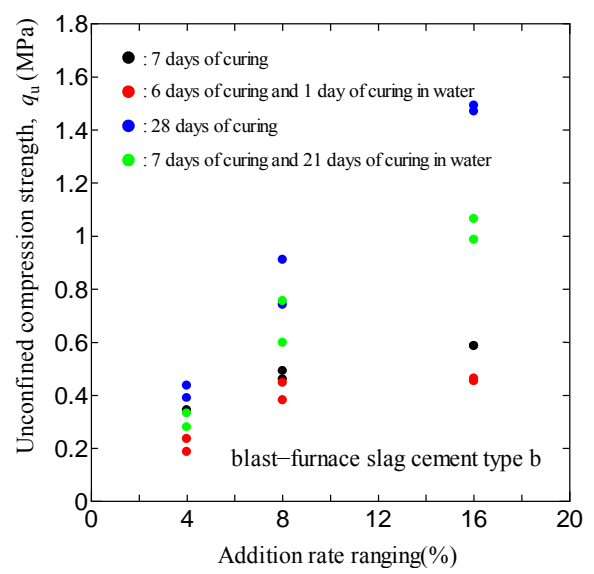

(b) Blast-furnace slag cement, type B

Fig. 9. Effect of cement proportion and curing period on uniaxial compressive strength

Uniaxial compression test and triaxial compression test with bender elements were carried out by using the specimens prepared at optimal water content after mixing with 4 to $16 \%$ of cement by weight. The two types of cement used in this research were, Portland cement and Blast furnace cement type B (produced by using 30 to $60 \%$ of blast furnace slag). 


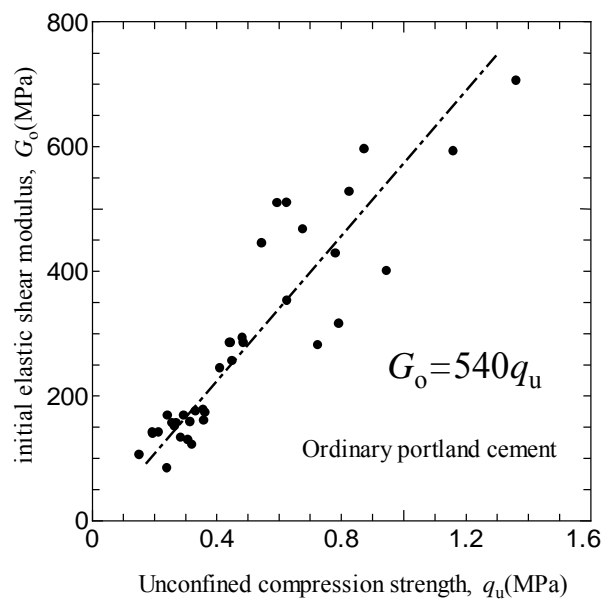

(a) Ordinary Portland cement

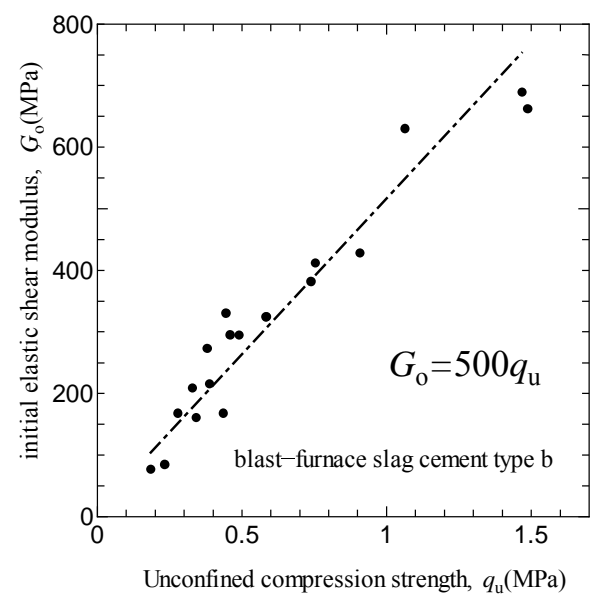

(b) Blast-furnace slag cement, type B

Fig. 10. Relationship between initial shear modulus and uniaxial compressive strength

Curing was done by adopting the following four methods. 1) 7 days sealed curing, 2) 6 days sealed curing and the last 1 day water curing, 3 ) 28 days sealed curing and 4) 7 days sealed curing and 21 days water curing. Fig. 9 shows the relationship between the uniaxial compressive strength and proportion of cement used. Difference due to curing methods are also represented. Fig. 10 is a graph showing the relationship between the initial shear modulus and uniaxial compressive strength for the same sample.

In contrast to the $\mathrm{q}_{\mathrm{u}} \approx 25 \mathrm{kPa}$ of disturbed samples, the cement improved soil after 7 days curing and with the minimum amount of cement added this time (4\%) showed comparatively large value of $\mathrm{q}_{\mathrm{u}}(200 \sim 400 \mathrm{kPa})$. This is considered to be the effect of chemical action of the cement bonding between soil particles. Another peculiar trend associated with these cement-added samples as shown in Fig. 10 is that there is a linear relationship between $\mathrm{q}_{\mathrm{u}}$ and $\mathrm{G}, \mathrm{G}=500 \sim 540 * \mathrm{q}_{\mathrm{u}}$, applicable to all samples regardless of the cement type, the cement proportion used and curing period.

\subsection{Differences of Polishing sand characteristics at natural state and after cement-mixing}

A unique relationship between Young's modulus of elasticity and compressive strength $\left(\mathrm{E} / \mathrm{q}_{\mathrm{u}} \approx 1,800\right)$ has been reported for the cement-mixed sand in the literature (Shibuya et al., 2001) regardless of mixing ratio of cementing material and the age of samples while curing. If isotropic behavior for cement mixed Polishing sand is assumed, i.e., $v=0.5, E=3 \mathrm{G}$, current value of shear modulus also falls in the same range. On the other hand, as described above, for the sample at natural state, the relationship between $\mathrm{G}$ and $\mathrm{q}_{\mathrm{u}}$ is nonlinear. Differentiating these two aspects is not so simple. However, undisturbed Polishing sand samples at their natural state show greater compressive strength $q_{u}$ as compared to the cement treated soil for the same shear modulus $G$. If linear relationship is assumed, $q_{u}=G / 150$ is obtained and it is clear that the coefficient 500 to 540 associated for cement-treated state is almost three times the value than that at its natural state. This is considered to represent a physical cementation effect comprised of recrystallization at molecular level at the soil particle surface.

\section{SUMMARY}

Polishing sand includes fine fraction of $90 \%$ with only 11 percent particles in the range of sand and is classified as the volcanic ash quality fine-grained soil. The particle size composition is therefore, not a so-called "sand". On the other hand, the soil has very low plasticity, as understood from the consistency indexes, liquid limit and plastic limit as NP. The average value of shear strength, $\mathrm{c}_{\mathrm{cu}}=10 \mathrm{kPa}$ and $\varphi_{\mathrm{cu}}=36^{\circ}$ of the reconstituted sample, are similar to the mechanical properties to the coarse-grained soil. This could be the reason why it is referred as "Polishing sand".

The strength parameters of Polishing sand in the natural state, $\mathrm{q}_{\mathrm{u}}=0.2 \sim 3.4 \mathrm{MPa}, \mathrm{c}_{\mathrm{cu}} \approx 100 \sim 200 \mathrm{kPa}$ and $\varphi_{\mathrm{cu}} \geq 40 \sim 50^{\circ}$ seems to be in a consolidated soft rock state.

Although in a soft rock state originally, it changes into a homogeneous grayish-white granular soil when drilled and exposed to the surface. The $q_{u}$ of the reconstituted sample reduces to $1 / 10-1 / 100$ of the natural state.

Polishing sand at natural state shows the effect of ageing in the form of cement bond development and crystallization between soil particles.

In the triaxial test with bender elements on undisturbed samples, possible anisotropy of soil structure in deposition has been confirmed from the ratio of shear moduli representing the stiffness in horizontal and vertical direction, $\mathrm{G}_{\mathrm{hh}} / \mathrm{G}_{\mathrm{vh}}=1.4 \sim 1.5$ under an average effective confining pressure, $\mathrm{p}^{\prime}=0 \sim 100 \mathrm{kPa}$.

In the effective confining pressure range of $100 \sim 400$ $\mathrm{kPa}$, anisotropy disappears with $\mathrm{G}_{\mathrm{hh}} / \mathrm{G}_{\mathrm{vh}} \approx 1.0$, suggesting the damage of cementation due to an 
increased applied effective pressure.

Measurement of shear modulus $\mathrm{G}$ by bender element test is a very effective method in evaluating the strength characteristics of undisturbed samples.

In this study, sample of Polishing sand at natural state and those improved by cement addition are compared by the relationship between elastic shear modulus and compressive strength. The difference has been considered to be physical cementation due to ageing.

At an identical shear stress-to-shear strain ratio (shear modulus), Polishing sand at its natural state displays three times or higher compression strength as compared to that of its cement treated state (due only to chemical cementation). It is believed to be the effect of additional physical effect of cementation due to ageing.

\section{REFERENCES}

1) Isobe, K.(1993):Polishing sand of Handa, Tsu-shi - About the history and origin, Tsu people's culture No. 20, pp. 50-57.

2) Japanese Standards and Explanations of Laboratory Tests of
Geomaterials, Japanese Geotechnical Society, p.96, 2009.

3) Kawajiri, S., Kawaguchi, T., and Shibuya, S.(2013) : Measurement and evaluation of elastic shear modulus of sandy geomaterial, Journal of the Society of Materials Science, Japan, Vol.62, No.1, pp.39-44.

4) Nishioka, T., Shibuya, S., Watanabe, H., and Okumura, T.(2015): The history and characteristic of Polishing sand, Journal of the Japanese Geotechnical Society (Submitted).

5) Shibuya, S. and Tanaka, H.(1996): Estimate of elastic shear modulus of Holocene soil deposits, Soils sand Foundations, Vol. 36, No.4, pp.45-55.

6) Shibuya, S., Mitachi, T., and Ozawa, H.(2001): Time/stresshistory dependency of deformation-strength characteristics of cement-mixed sand, Japan Society of Civil Engineers (No. 687/III-56), 249-257.

7) Yoshida, S.(1987):Geological feature memoir of the Tsu eastern part in Japan (1:50,000 Scale), Geological survey of Japan, p.33.

8) Yoshikawa, S.(2001): Tephrostratigraphy of the Tokai Group on Ise Plain, central Japan, Shimane University earth resources environmentology memoir, Vol. 20, 59-67. 